\title{
Non-Formal Vocational Education for Pineapple Farmers: Promoting 'Relevance' of Education to Rural Economy
}

\author{
Wanwisa Suebnusorn* \\ Panyapiwat Institute of Management, Nonthaburi, Thailand
}

\begin{abstract}
Canned-pineapple is one of the most important exports of Thailand. Unfortunately, the more pineapples the farmers cultivate, the more they are likely to fall into debt and become poorer. Therefore, in 2011, the Phetchaburi College of Agriculture and Technology in collaboration with Kuiburi Fruit Canning Company Limited initiated a non-formal vocational education program tailored to the pineapple farmers who were normally in the age between 40 and 60 . The primary aims of the program were to build trust between the farmers and the factories and to equip the farmers with necessary skills for pineapple planting as per the demands of the pineappleprocessing factories. Through field visits, semi-structured interviews, and a focusgroup interview with the stakeholders, this study sheds lights on the relevance of education to the demands of rural economy which transcends the traditional preparation of employees for rural economic sectors. The well-educated farmers who understand their roles in the farming stage of the food industry's value chain are as important as formal workers or employees in the breeding, the post-harvest, the production process, as well as the marketing and logistics stages of the value chain. Therefore, non-formal vocational education for the rural labour market should by no means be confined to formal workers in the downstream of the value chain. Informal workers or farmers in the upstream of the value chain have crucial impact on its subsequent stages. Above all, being empowered by relevant nonformal vocational education, the roles of farmers in advancement of rural economy should be extended beyond farming.
\end{abstract}

Keywords: Non-Formal Vocational Education; Pineapple Farmers; Thailand; Rural Economy

\section{Introduction}

Food-processing industry, especially canned-pineapple industry, is one of the most important export industries in Thailand. In the last decade (2001-2010), Thailand had been the second largest, after Brazil, pineapple producer in the world and therefore had

* Author email: kunkrujairai@hotmail.com

ISSN: 2091-0118(Print)/2091-2560(Online)

(C) 2016 JER 
also been the world's leading pineapple exporter (FAOSTAT, 2010, as cited in Novagrim, 2011). Unfortunately, pineapple farmers in the country have experienced a tremendous challenge, which, in their own words, is characterized as "the more they cultivate, the more they get into debt and become poor" (Pineapple farmer 1, personal communication, 13 February 2013). Many pineapple farmers do not know how to reduce the costs, how to increase the productivity, and how to produce the pineapples that meet the demand of the canned-pineapple factories. Although the factories have tried their best to communicate their demands to the pineapple farmers, the farmers have generally viewed this practice sceptically. And given the low selling prices, road-blocking protests by thousands of farmers is still common in Thailand.

Therefore, in 2011, the Phetchaburi College of Agriculture and Technology in the lower-central part of Thailand initiated a non-formal vocational education program tailored to the pineapple farmers who were normally in the age between 40 and 60 and completed at least lower-secondary education or nine-year-compulsory education. The primary aims of the program were to build trust between the farmers and the factories as well as to equip the farmers with necessary skills for better pineapple planting and commercialization. The college collaborates closely with Kuiburi Fruit Canning Company Limited and learners have a great opportunity to learn at the college, in the pineapple fields, as well as in the factory. After completion of 17 months of study, they will be awarded Vocational Certificate of Agriculture in Pineapple Planting, which is equivalent to the upper-secondary education. They will also have a chance to pursue Diploma Certificate of Agriculture in Pineapple Planting, which takes one and a half year to complete and is equivalent to the diploma level of the higher education system. The program is a part of the Vocational Education for Rural Development Project of the Ministry of Education during the second decade of the educational reform (2009-2018). It is also considered as one of the most successful models of college-industry collaboration. The learners reported that they have been equipped with necessary competences as stated in the curriculum. Beyond that, they have learned to solve the low-buying price problem as an "educated person," not by blocking a road like before (Pineapple farmer 2, personal communication, 13 February 2013). Unfortunately, this program is now being offered only to the pineapple farmers in Phetchaburi and other nearby provinces. The college also has limitations as a provider of the program at the bachelor level in spite of expectation of the current students (Director of Phetchaburi College of Agriculture and Technology, personal communication, 12 February 2013).

This current study is a follow-up study of an unexpected result found from the project entitled "Innovative Models for Fostering Relevance of Education to the Labour Market at the Provincial Cluster Level," commissioned by the Ministry of Education of Thailand and was conducted by the author and research team at the Labour Development Division of Thailand Development Research Institute (TDRI) during July 2012-April 2013. It was 
considered an "unexpected" result because the said research project focused on schoolage students and formal education. The aims of this follow-up study conducted in August 2014 were: (a) to explore sustainability of this non-formal vocational education program; and (b) to study further whether and how this program could be scaled up or replicated in the College of Agriculture and Technology in other pineapple planting provinces such as Chiang Rai and Lampang in the Northern part of Thailand. The possibility to extend the program to the bachelor level was also explored. Above all, this paper is a tentative starting point from which to consider significance of non-formal vocational education to development of farmers as informal workers who can respond to the demands of both the upstream and downstream of the value chain of the food industry.

\section{Key Concepts}

Taking into account the goal of non-formal education program discussed in this paper, the first important concept that should be considered is the dependency-liberation theory. It explains how the farmers can respond well to the demands of the rural economy and at the same time extend their roles in the food value chain beyond farming. Then, sustainability and ability to scale up the program that are the aims of this follow-up study can be viewed through the lenses of other relevant concepts including motivation of adult learners, competency-based curriculum, and college-industry collaboration.

\section{Dependency-Liberation Theory}

Non-formal education could be conducted in different forms. Examples of such form practiced worldwide include agricultural extension, community development, and technical/ vocational training, etc. with the view to improve power and status of the disadvantaged urban and rural adults who are unable to access formal education. Seeing through the lens of the dependency-liberation theory, the life of farmers is conditioned by the decisionmaker elites in terms of what they produce and the price that they receive for their products, the technology they need to use for farming, and the legal system within which they must function. As a result, education for liberation should allow farmers to overcome domination and vulnerability (Belle, 1984). While early proponents of the dependency-liberation theory were not definitive as to how educational programs can respond to dependency conditions, Paulo Freire proposed conscientisation or consciousness raising. Individuals could be aware of their reality, they can reflect, and critique it because they are a "subject," not "object" of reality (Freire, 1974, as cited in Belle, 1984).

Taken the dependency-liberation orientation, the non-formal vocational education program for the pineapple farmers presented in this paper responds to the capitalist economic system while encouraging farmers' independence on wider political and economic processes that determine demands of the food industry. It could also be said that the pineapple farmers excel in farming and attend to intermediaries and the demand of the 
marketplace, and that their roles in the value chain of the food industry go beyond farming. In the 21st century, vocational education has gone through various tremendous changes. In the Czech Republic, for example, the traditional emphasis on knowledge of agricultural production has evolved into emphasis on the ability of learners to understand the human's food chain and to possess relevant managerial skills (Slavik, 2004).

In the time-honoured words of Bock (1976), "the capacity of education to transform the competencies of individuals may not be as important as its capacity to transform their future prospects, and that the latter does not necessarily follow from the formers" (p. 356). However, once they are schooled, they have been provided with a legitimate claim to the right of allocation to authoritative societal roles because they are differently defined by the society (Bock, 1976). Fielke and Bardsley (2014) confirmed that in the South Australian agricultural sector, further "formal" education equips farmers with the ability to compete effectively in a liberalised economy. However, the collapse of formal economies such as in sub-Saharan Africa, suggests that higher social rates of return from education might accrue from investment in "non-formal" adult education that aims at enhancement of skills and labour productivity of rural populations (Minnis, 2006).

\section{Motivation of Adult Learners}

Adult learners are "the agents of individual choice" (Coleman, 1990, as cited in Boeren\& Holford, 2016, p. 123). Given this, it can be said that the possibility to scale-up the non-formal vocational education program for pineapple farmers and its sustainability are highly determined by the motivation to learn of current and prospective pineapple farmers. A widely cited classification of adult learner by Houle (1961) distinguished three types of adult learners: (a) those interested in concrete goals or improving their status in the labour market, (b) those driven by social interactions within the group of learners, and (c) those participating because of their strong intellectual interest in the course.

\section{Competency-Based Curriculum Through College-Industry Collaboration}

This paper assumes that the non-formal vocational education program for pineapple farmers discussed here can promote relevance of education to rural economy as well as empower farmers because it uses competency-based curriculum, which is "an educational paradigm in which the competences (e.g., skills, knowledge, and attitudes) needed in later professional practice form the basis for curriculum development instead of academic subjects, such as English or mathematics" (Wijnia, Kunst, van Woerkom, \& Poell, 2016, p. 115).

The program also promotes factory-college collaboration and learning at the college, in the pineapple fields, and in the factory. When non-formal education combines everyday environment of the learners with their learning, their learning will substantially contribute to the improvement of their behaviour (Belle, 1982). Activities that create "demand" 
for new learning and skills might lie outside education. Educators should do more to raise the demand for learning from the social setting and human interaction through inter-sectorial fluency in education or connection between the real life and the world of education (Easton, 2014). It has also been noted that in order to respond to the everchanging economic environment, learners should be integrated with practical industrial experiences, which helps close the gap between vocational education and the practical demands of industries (Chung, Yeh, \& Chen, 2016). As found in Indonesia, unless farmers are additionally provided with access to laboratory, green house, and field works, they will not be able to have sufficient understanding and experience as breeders and seed producers (Rostini\&Hindersah, 2012).

\section{Methods}

Based on interpretivism as a research paradigm, results presented in this paper mainly rely on primary data gained from thirteen key informants through face-to-face semistructured interviews, a focus-group interview, and field visits in February 2013, followed by five follow-up telephone semi-structured interviews in August 2014. Since the nonformal vocational education for pineapple farmers was just initiated in Thailand in 2011, earlier research regarding the program, as far as I am aware, is scarce. Primary data, especially from the point of views of the stakeholders, are very useful for the analysis of this program that is considered innovative in Thailand.

The research started with semi-structured interviews with the Director of the Phetchaburi College of Agriculture and Technology (male in his late 50s) and the field visit at the college on 12 February 2013. Then, the research team of four researchers visited Kuiburi Fruit Canning Company Limited on the next day in order to observe the site and conduct a focus-group interview with two human resource managers of the company and six students of the program who were pineapple farmers. The college and the factory selected those students for the focus group without intervention from the research team. All of the interviewees in this phase were male. Two of them were in their 40s. The other three were in their 50s. The oldest one was in his $60 \mathrm{~s}$. Moreover, they were not the firstgeneration farmers. In other words, they grew up in the family of pineapple farmers

Then, a year later, in August 2014, I conducted a follow-up telephone interview with the Director of the college in order to update the signs of progress and challenges of the program. In the same month, I also conducted telephone interviews with three senior officials of the Ministry of Education. The first one was at that time the director of an educational service area in the Northern part of Thailand (male in his late 50s). The other two officials were considered policy makers in this research. They represented the Office of the Vocational Education Commission (female in her early 60s) and the Office of the Education Council (female in her late 50s), respectively. One of the female key informants had at that time recently retired from the MOE but had been still employed by the Ministry 
of Education as a senior advisor. In addition, I conducted a telephone interview with a pineapple farmer in Lampang province (female in her 50s) in order to see how she viewed this program. In this phase of the research, the telephone interview was unavoidable because at that time I was not in Thailand. All interviewees in this phase were purposively selected. I knew them personally through my professional experience and I was confident that they were at that time the best key informants who could provide insights regarding the possibility to scale up the program in other pineapple planting provinces in Thailand.

The interview results were analysed through thematic analysis and were supplemented by an exhaustive review of relevant documents in order to identify the significance of the program, its aims and objectives, its innovative strategies, key success factors, obstacles and challenges, and possibility to be replicated in other parts of Thailand.

\section{Significance of the Vocational Certificate of Agriculture in Pineapple Planting}

Through the lens of the dependency-liberation theory, this vocational certificate program is vital to Thailand for two reasons. First, Thailand is the world's major food and agricultural products exporter and the country wishes to be the "kitchen of the world." Second, there are a considerable proportion of Thai labourers working in the agricultural sector who require a continuing education for their better quality of life.

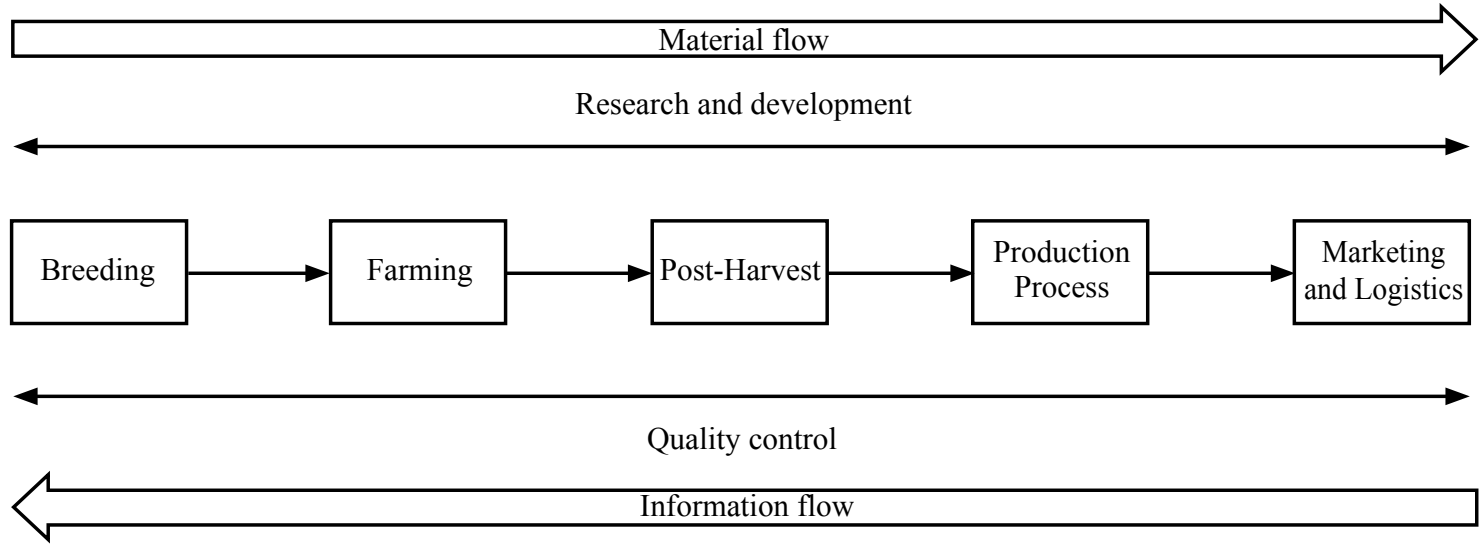

Figure 1. Value chain of the food industry (Adapted from TDRI, 2012).

Considering the value chain of the food industry (Figure 1), it is undeniable that the pineapple farmers are important actors in the value chain if Thailand wants to be the "kitchen of the world." High-quality raw materials have a significant impact on the quality and added-values of the final food products. In addition, since research and development (R\&D) should be done throughout the value chain, the farmers need to be better educated so that they can excel in planting and act as researchers seeking for creative planting techniques. Farmer-factory collaboration offered by this non-formal vocational education program is also very useful to bridge the gap between the demand of the factories and the supply of pineapples provided by the farmers. The college also hopes that pineapple 
farmers will be able to sell fresh pineapples directly to the consumers in markets by themselves. Nowadays, they still rely very much on selling their products to pineappleprocessing factories (Director of Phetchaburi College of Agriculture and Technology, personal communication, 5 August 2014). This means that the pineapple farmers should learn to engage in other stages of the value chain, too.

In terms of the need to improve the well-beings of the farmers, the Thai often say that "farmers are the backbone of the nation." The Labour Force Survey in December 2015 demonstrated that there were 38.87 million employed persons, among whom 13.63 million (35.07 percent) were in the agricultural sector and 25.24 million (64.93 percent) were in the non-agricultural sector (National Statistics Office of Thailand, 2015). A total negative growth rate of labourers in the agricultural sector had been observed during 1991-2010. However, among those who obtained the lower secondary education to the bachelor's degree, the growth rate in the agricultural sector had outperformed the growth rate in the industry and the service sector. The observation of the growth rate of agricultural workers with elementary and less than elementary education showed a decreasing trend, implying that the agricultural sector has no longer been reserved for non-educated workers as the society usually perceives (Chalamwong, Hongprayoon, \&Suebnusorn, 2012). Regrettably, the Royal Thai Government (RTG) has not yet well expanded its social security welfare schemes to encompass informal workers such as those who are working in the farms or fisheries while their formal worker counterparts are enjoying an increase in the daily minimum wage of 300 Baht and the Social Security Fund (TDRI, 2013). Following the dependency-liberation theory, it can be noted that providing relevant education, especially vocational education, may help these informal workers to access better quality of life.

Unfortunately, despite various educational programs offered, vocational education has been viewed as a second-class educational track for low achievers and has been unable to attract as many students as the country needs. Therefore, the RTG has initiated various innovative strategies to attract both traditional and non-traditional students to pursue vocational education. The Agricultural Education for Life Program, a free boarding school program, has been introduced since 1995 and survives until today in order to produce good quality future farmers. The program collaborates with local communities in student recruitment process. Students are offered practical experiences in planting and self-employment activities through project-based learning and are provided with free accommodations and meals as well as funds for investment in self-employment agribusiness. Key success factors of the Agricultural Education for Life are free boarding school, learning by doing and earning, and willingness for hardworking of both teachers and students (Choomnoom, Nguyen, Chan, \& Dyna, 2012). However, this program is offered only to the traditional students in the form of formal education. The Vocational Certificate of Agriculture in Pineapple Planting of the Phetchaburi College of Agriculture and Technology added innovativeness in terms of collaboration with the food industry 
and targeting at the non-traditional students or current farmers. The program is a part of the Vocational Education for Rural Development Project of the Ministry of Education, which was originated from the former Vocational Education for Rural Poverty Reduction Project. These two programs target adult workers in the agricultural sector. The Vocational Education for Rural Poverty Reduction Project recruited primary education school leavers to train in the Certificate of Vocational Education special program for five years. However, upon completion, those students were unable to use the certificate for pursuing their education at the higher level. The Vocational Education for Rural Poverty Reduction Project has then been changed to the Vocational Education for Rural Development Project, which recruits lower-secondary education graduates to pursue three-year Certificate of Vocational Education and the graduates of this three-year program can use the certificate for higher learning (Ministry of Education, 2010). The program is offered to students free of charge as it is a part of the twelve-year basic education.

\section{Aims and Objectives of the Programme}

As illustrated by the Director of the Phetchaburi College of Agriculture and Technology (personal communication, 12 February 2013), this program was initiated with the will to use education as a means to promote mutual trust between the pineapple-processing factories and the pineapple farmers. The primary aims are to enable pineapple farmers to: (a) increase productivity to ten tons per 1,600 square meters; and (b) deliver high-quality pineapples that meet the requirements of the food industry. Pineapple farmers are likely to overuse chemical fertilizers and this creates undesirable chemical reaction with cans when the pineapples are processed as canned-pineapples. In addition, the pineapple farmers rarely gain any benefits from their financial and labour investment. From the perspective of the dependency-liberation theory, the program initially aims at adjustment of farmers to circumstance of the food industry. However, ability of farmers to liberally seek for better quality of life by themselves are not neglected. As in the case of Czech Republic (Slavik, 2004), it similarly happens in Thailand that agricultural studies are involving farmers' understanding of human's food chain and farm business management and economics.

\section{Innovative Strategies of the Programme}

The non-formal vocational education program presented here employed several innovative strategies. They are college-industry collaboration, competency-based curriculum, team teaching, and work-based learning as described in greater detail below.

\section{College-Industry Collaboration}

As evidenced by current literature in the context of other countries such as Taiwan (Chung et al., 2016) and Indonesia (Rostini\&Hindersah, 2012), this non-formal vocational education program for pineapple farmers in Thailand is another evidence of contributions 
of college-industry collaboration. As far as I am aware, this program is the most concrete example of collaboration between the food industry and the educational institutions in vocational education in Agriculture in the lower-central provincial cluster 2, which consists of Phetchaburi Province, Prachuapkhirikhan Province, SamutSakhon Province, and SamutSongkhram Province, and even in the whole country. According to the Vocational Education Act 2008, vocational education can be provided in three forms: formal education, non-formal education, and dual vocational education. College-industry collaboration in Agricultural program has not been widely observed even in the forms of formal education and dual vocational education. Thus, this non-formal vocational education program is considered relatively innovative.

The Kuiburi Fruit Canning Company Limited is responsible for advertising the program in order to attract new students by targeting pineapple farmers and the young lowersecondary education school leavers who intend not to pursue upper-secondary education. The company provides scholarships (86,000 Baht per student), meals, and learning facilities to the new graduates of the certificate program who want to continue the pineapple planting programs at the diploma level. The college acts as the intermediary between the farmers and the factory so that both the farmers and the factory gain mutual benefits. Kuiburi Fruit Canning Company Limited is offered financial incentives from the RTG in forms of tax redemption for the industrial sector that takes part in educational provision and is supplied high-quality fresh pineapples from the farmers. The farmers also learnt to produce pineapples as per the demands of the factory and learnt to create more profits from their pineapple planting (Human Resource Managers of the Kuiburi Fruit Canning Company Limited, personal communication, 13 February 2013).

\section{Competency-Based Curriculum, Team Teaching, and Work-Based Learning}

The Vocational Certificate of Agriculture in Pineapple Planting adopted the core curriculum prepared by the Office of Vocational Education Commissionbut the college and the factory collaboratively adjusted it so that it is tailored to suit the characteristics and needs of the pineapple farmers. The curriculum is a competency-based one. Although the farmers need to learn core subjects such as Mathematics, Thai, English, and Computer quite similar to other students in the formal education system, these subjects are tailored to the context of their agricultural occupations. Duration of the program is 17 months as equal as the duration of pineapple planting. Students are offered lessons every alternate Saturday. In the first year, students learn at the college and in the factory. Then, in the next half year, they learn in the pineapple fields. At the end of each semester, students must present their learning outcomes at the term-end seminar.

A team of five teachers from the college is sent to provide team-teaching at pineapple fields or houses of the farmers. The teaching technique is unique. The teachers offer a lesson at the first house, then repeat the lesson again at the second house, the third house, 
until the eighth house in one day. Students must learn at their own house and all their classmates' house. In other words, students need to learn the same lesson eight times per day so that they learn to be patient and learn to share their knowledge with their classmates. In addition, the college arranges technical visits to pineapple fields in other provinces such as Rayong, Chonburi, and Ratchaburi in order to facilitate knowledge exchange between the farmers at Phetchaburi and pineapple farmers in other provinces. The farmers also have a chance to study fruit-processing process in the factory so that they can deeply understand the demands of the factory. Last but not least, the "Mr. Pineapple" position is also awarded to the outstanding pineapple farmers in each educational service area. As a response to a recent research by Boeren and Holford (2016), which indicated that motivation to learn of adult learners is determined by the contexts in the country rather than the characteristics of individuals. Moreover, awarding Mr. Pineapple might arouse motivation to learn among the current pineapple farmers who have not yet joined the program.

\section{Key Success Factors}

Based on the focus-group interview with six students and two representatives of the factory (personal communication, 13 February 2013), the program is highly successful in terms of meeting the demands of both the students and the factory and promoting mutual understanding between them. There were 27, 30, and 20 students in academic year 2011, 2012, and 2013 respectively. Some of the first cohort students who enrolled in 2011 pursued their study in this program at the diploma level, which was later launched in 2012. Now, the first group of students who enrolled at the diploma level have also graduated and wish to pursue the Bachelor's degree in Agriculture (Pineapple Planting). This is one of the most important demands of students that they want the research team to communicate to policy makers at the Ministry of Education.

Students reported further that the program enhanced their systematic thinking skills. Now they learned how to cut the costs and increase productivity. In the past, many farmers believed that putting more fertilizers would increase productivity, but, in reality, this created too much nitrate in the pineapple and increased unnecessary costs. Since the program offered them a chance to learn the pineapple-processing process in the factory, they learned that too much nitrate leads to unwanted chemical reaction with the can and understood why the factory had rejected their pineapples in the past. In addition, students learned to keep records regarding their pineapple planting so that they could calculate the costs, and learned to plan their pineapple cultivation properly both in terms of quantity and quality. Above all, they touchingly expressed that now "we are educated. We know how to deal with the low selling price as an educated person. We know how to write official letters and no longer block the street like before" (Pineapple farmer 2, personal communication, 13 February 2013). According to the dependency-liberation theory, their words implied that they are now learning to liberalize themselves from the influences of the decision-maker elites. 
As reported by the Director of the college (personal communication, 12 February 2013), there were two important success factors of the program. The first one was the revered status of teachers in the Thai society. In the past, the factory had constantly tried to communicate their demand with the farmers but the farmers did not trust the factory. On the contrary, they believed in the teachers. The college and teachers accordingly acted as the middlemen between the factory and the farmers. Similar to the key success factor of the Agricultural Education for Life program established in 1995 as mentioned earlier, the second key success factor was the hardworking teachers. Since the budget and number of teachers provided by the government were not sufficient, the current teachers needed to be motivated to work harder even though the benefits that they received were not able to keep pace with their efforts. For example, the teachers needed to seek for vehicles and pay for transportation to students' pineapple fields by themselves.

\section{Obstacles and Challenges}

Although current literature such as Easton (2014) called for the demand-driven nonformal education, the Director of the college listed the following obstacles and challenges that reflected constraints of the program both in terms of the demand side (i.e., students and economy) and the supply side (i.e., college and education providers) (personal communication, 12 February 2013):

\section{Demand Constraints}

1. Decreasing numbers of farmers in Thailand. The current pineapple farmers are generally in old age (above 40 years) and the young workers are not interested in the agricultural works.

2. Increasing land price. Phetchaburi and Prachuapkhirikhan are two of the most important tourist attractions of Thailand. The land price in these provinces is increasing as many patches of land are now being demanded for real estates. And that farmers are persuaded to sell their lands.

3. Low selling price of pineapples. Many farmers are currently attracted by other industrial crops due to low selling price of pineapples.

4. Lack of the lower-secondary education certificate of the farmers. Since the program is provided at the certificate level, those who are interested in the program need to complete at least lower-secondary education. Unfortunately, many current farmers in Thailand have completed only elementary education or even lower grade levels.

\section{Supply Constraints}

1. Limited scope of program's advertisement. The advertisement for the program is still unsuccessful. 
2. Insufficient budgets and limited numbers of teachers. As mentioned earlier, the budgets and teaching staff for this program are still insufficient. Since the program is a nonformal education program, teachers need to go to teach at the students' pineapple fields during their weekend with little extra payment and no transportation services provided by the college. The college also experiences a shortage of teaching buildings. It is fortunate that the factories are now supporting teaching rooms and learning facilities.

3. Lack of involvement and supports from other government agencies. Education and training for farmers are under the responsibility of various government agencies, not only the Ministry of Education. However, the other government agencies such as the Ministry of Agriculture and Cooperatives have not yet been active in providing education to the farmers. The Ministry usually provides only the short-term training programs to the farmers.

As further reported by the students (personal communication, 13 February 2013), the main challenges to them are the core subjects such as mathematics, Thai, and English. They are in their old age and had left the formal education system for at least 20-30 years. To them, it is extremely difficult to follow these subjects although the curriculum has been already adjusted to become a competency-based curriculum. Their opinion proves that the competency-based curriculum is possibly the best choice for non-formal vocational education for adults because they excel in skills required for their occupation more than academic subjects. In addition, it is difficult to persuade other pineapple farmers to enrol in this program. As reported by a student farmer, "Other farmers are so stubborn. No matter how much the government has tried to introduce the planting techniques or provide further training, they still insist on planting in the ways they are familiar with" (Pineapple farmers 3, personal communication, 13 February 2013).

\section{Possibility to Scale up the Programme}

Based on the additional interviews with three officials of the Ministry of Education and a farmer in the Northern part of Thailand in August 2014, the program is well acknowledged by the officials but the interviewed farmer is still skeptical about the program. From the perspectives of an official of the Office of the Education Council (personal communication, 15 August 2014), the program is well structured and can be used as an example to other vocational education programs in terms of the strong linkage between the industrial sector and the educational institutions. The possibility to scale up the program at the bachelor's level is also well received as far as the curriculum is competencybased and at least 50 percent of the instruction is arranged at the workplace (An official of the Office of the Vocational Education Commission, personal communication, 5 August 2014).

An official of the Office of the Vocational Education Commission (personal communication, 5 August 2014) foresaw the need for agricultural production planning 
between the factory and the farmers in order to avoid over-supply of pineapples and other industrial crops such as mangosteen and rambutan. Nevertheless, a director of an educational service area in the Northern part of Thailand (personal communication, 11 August 2014) realized that education alone cannot solve the low selling price problem as the prices are not only determined by the demand and supply or the quality of the agricultural products, they are mostly intervened by the foreign middlemen in the market. His opinion confirmed the dependency-liberation theory that it is unavoidable that educators should take into account internal and external forces that affect farmers although they aim at liberalizing farmers from such influences.

One of the interviewee farmers from the Northern parts of Thailand has experienced that pineapples from Lampang are not well demanded by the factories compared to pineapples from the lower-central and Southern parts of Thailand. Pineapple farmers in Lampang usually sell their products to consumers of fresh pineapples. In terms of her intention to take part in the program, she felt that she is too old to attend further schooling and many farmers in Lampang did not complete the lower-secondary education (Pineapple farmer 7, personal communication, 20 August 2014). According to three types of adult learners classified by Houle (1961), it can be said that she is not interested in improving her status in the labour market. She has no learning networks. In addition, she has no cognitive interest in the agricultural study. If her opinion represents the voice of the majority of pineapple farmers in Thailand, the sustainability and possibility to scale up the program might not be as easy as expected.

\section{Conclusion}

To the policymakers and practitioners in the field of non-formal vocational education for rural economic development who are my primary target audiences, this paper documents an evidence that efforts of policymakers and practitioners to promote the relevance of education to rural labour market should go beyond education for "formal workers" or employees for rural economic sectors. Such relevance can also be promoted by providing education for "informal workers" such as farmers through college-industry collaboration. As farmers are at the upstream of the value chain of the food industry, their competences will have impacts on the downstream of the value chain. Once the college successfully creates farmers who can produce quality pineapples, their knowledge and skills other than farming are important for their survival in the value chain of the food industry. As could be seen, the college gradually encourages farmers to learn production processes in the factory and assists them in the marketing of their fresh pineapples directly to the consumers. In addition, this non-formal vocational education demonstrates that competency-based curriculum and college-industry collaboration that have been promoted by the policy makers are the right choices for non-formal vocational education for rural economy. However, practitioners are facing many challenges in the process of 
implementing these pedagogical practices both in terms of the supply constraints and the demand constraints. By looking at the success factors of the program, this study suggested that in order to scale-up the program, teachers at the college are the main contributors.

To the academic community, this study is not theoretically oriented but it provides a further empirical evidence in the context of Thailand that proves assumptions of academic proponents of the dependency-liberation theory, competency-based curriculum, and college-industry collaboration. Interviews with the farmers also enhanced the body of knowledge regarding factors affecting motivation to learn of adult learners.

Finally, to researchers, this study implied that the roles of farmers in the rural economic advancement should go beyond farming. However, concrete pieces of evidence to suggest how education can help them reach that goal are still insufficient.

By and large, although this study does not aim to provide theoretical novelty, the nonformal vocational education program for pineapple farmers is innovative by itself. It is worth to be documented and scrutinized based on proper theoretical frameworks as Drucker (1985) noted, every practice rests on theory, even if the practitioners themselves are unaware of it. This program should be scaled-up because its aims and fundamental practices are supported by well-established theories.

\section{Acknowledgements}

This paper is the product of a broader study entitled "Innovative Models for Fostering Relevance of Education to the Labour Market at the Provincial Cluster Level." I would like to thank the Office of the Education Council, Ministry of Education, Thailand for the research funding. This paper was originally presented at the 5th Education for Rural Transformation (ERT) International Symposium "Reengineering Education for Flexible Learning and Social Justice" jointly organized by School of Education, Kathmandu University and Institute of International Education, Stockholm University on 17-19 September 2014 in Dhulikhel, Nepal.

\section{References}

Belle, T. J. L. A. (1982). Formal, non-formal and informal education: A holistic perspective on lifelong learning. International Review of Education, 28(2), 159-175.

Belle, T. J. L. A. (1984). Liberation, development, and rural non-formal education. Anthropology \& Education Quarterly, 15(1), 80-93.

Bock, J. C. (1976). The institutionalization of non-formal education: A response to conflicting needs. Comparative Education Review, 20(3), 346-367.

Boeren, E., \& Holford, J. (2016). Vocationalism varies (a lot): A 12-country multivariate analysis of participation in formal adult learning. Adult Education Quarterly, 66(2), 120-142. 
Chalamwong, Y., Hongprayoon, K., \& Suebnusorn, W. (2012). Innovative secondary education for skills enhancement: Skills for employability - Southeast Asia. Retrieved from http://r4d.org/sites/resultsfordevelopment.org/files/resources/Skills\%20for\%20 Employability\%20in\%20Southeast\%20Asia.pdf

Choomnoom, S., Nguyen, A. D., Chan, S., \& Dyna, H. (2012). Innovative secondary education for skills enhancement: Innovative models for skills enhancement-Southeast Asia. Retrieved from http://r4d.org/sites/resultsfordevelopment.org/files/resources/ Inno vative $\% 20$ Models\%20in\%20Southeast\%20Asia.pdf

Chung, P., Yeh, R. C., \& Chen, Y. C. (2016). Influence of problem-based learning strategy on enhancing student's industrial oriented competences learned: An action research on learning weblog analysis. International Journal of Technology and Design Education, 26, 285-307.

Drucker, P. F. (1985). Innovation and entrepreneurship: Practice and principles. New York, NY: Harper \& Row.

Easton, P. B. (2014). Developing literate environments: Fleshing out the demand side of education for all. International Journal of Educational Development, 34(1), 3-10.

Fielke, S. J., \& Bardsley, D. K. (2014). The importance of farmer education in South Australia. Land Use Policy, 39, 301-312.

Houle, C. O. (1961). The inquiring mind. Madison, WI: University of Wisconsin Press.

Novagrim. (2011). Pineapple statistics. Retrieved from http://www.novagrim.com/Pages 12000_2011_pineapple_statistics_EN.aspx

Ministry of Education. (2010). Vocational education for rural development project. Retrieved from http://www.moe.go.th/moe/th/news/detail.php?NewsID=19986\&Key=n ews2

Minnis, J. R. (2006). Non-formal education and informal economies in sub-Saharan Africa: Finding the right match. Adult Education Quarterly, 56(2), 119-133.

National Statistics Office of Thailand. (2015). Summary of the labor force survey in Thailand: December 2015. Retrieved from http://web.nso.go.th/en/survey/data_survey/ 050259_summary_December58.pdf

Rostini, N., \& Hindersah, R. (2012). Distance learning for pepper and corn breeding and seed production. Procedia - Social and Behavioral Sciences, 67, 380-385.

Slavik, M. (2004). Changes and trends in secondary agricultural education in the Czech Republic. International Journal of Educational Development, 24(5), 539-545.

Thailand Development Research Institute. (2012). The strategy for production and development of manpower for the industrial sectors. Bangkok, Thailand: Office of the Industrial Economy. 
Thailand Development Research Institute. (2013). Academic says government must do more for informal workers. Retrieved from http://tdri.or.th/en/tdri-insight/academic-saysgovt-must-do-more-for-informal-workers/

Wijnia, L., Kunst, E. M., van Woerkom, M., \& Poell, R. F. (2016). Team learning and its association with the implementation of competence-based education. Teaching and Teacher Education, 56, 115-126. 